\title{
Hypoglycemia and Outcome in Critically Ill Patients
}

\author{
Moritoki Egi, MD; Rinaldo Bellomo, MD; Edward Stachowski, MD; Craig J. French, MD; \\ Graeme K. Hart, MD; Gopal Taori, MD; Colin Hegarty, Bsc; and Michael Bailey, PhD
}

OBJECTIVE: To determine whether mild or moderate hypoglycemia that occurs in critically ill patients is independently associated with an increased risk of death.

PATIENTS AND METHODS: Of patients admitted to 2 hospital intensive care units (ICUs) in Melbourne and Sydney, Australia, from January 1, 2000, to October 14, 2004, we analyzed all those who had at least 1 episode of hypoglycemia (glucose concentration, $<81 \mathrm{mg} / \mathrm{dL}$ ). The independent association between hypoglycemia and outcome was statistically assessed.

RESULTS: Of 4946 patients admitted to the ICUs, a cohort of 1109 had at least 1 episode of hypoglycemia (blood glucose level, <81 $\mathrm{mg} / \mathrm{dL})$. Of these 1109 patients (22.4\% of all admissions to the intensive care unit), hospital mortality was $36.6 \%$ compared with $19.7 \%$ in the 3837 nonhypoglycemic control patients $(P<.001)$. Even patients with a minimum blood glucose concentration between 72 and $81 \mathrm{mg} / \mathrm{dL}$ had a greater unadjusted mortality rate than did control patients $(25.9 \%$ vs $19.7 \%$; unadjusted odds ratio, 1.42; 95\% confidence interval, 1.12-1.80; $P=.004$.) Mortality increased significantly with increasing severity of hypoglycemia $(P<.001)$. After adjustment for insulin therapy, hypoglycemia was independently associated with increased risk of death, cardiovascular death, and death due to infectious disease.

CONCLUSION: In critically ill patients, an association exists between even mild or moderate hypoglycemia and mortality. Even after adjustment for insulin therapy or timing of hypoglycemic episode, the more severe the hypoglycemia, the greater the risk of death.

Mayo Clin Proc. 2010;85(3):217-224

APACHE = Acute Physiology and Chronic Health Evaluation; AUC = area under the curve; $\mathrm{CI}=$ confidence interval; $\mathrm{ICU}=$ intensive care unit; IIT = intensive insulin therapy; NICE-SUGAR = Normoglycemia in Intensive Care Evaluation-Survival Using Glucose Algorithm Regulation; $\mathrm{OR}=$ odds ratio

$\mathrm{U}$ ntil recently, intensive insulin therapy (IIT) had been recommended to improve patient outcome ${ }^{1-3}$ despite its association with an increased risk of hypoglycemia. ${ }^{4-11}$ However, hypoglycemia, like hyperglycemia, ${ }^{12-16}$ has emerged as a possible predictor of mortality and morbidity in critically ill patients. ${ }^{5,17-21}$

The NICE-SUGAR (Normoglycemia in Intensive Care Evaluation-Survival Using Glucose Algorithm Regulation) trial found that IIT increased 90-day mortality compared with conventional treatment in critically ill patients. ${ }^{22,23}$ In that trial, the incidence of severe hypoglycemia (blood glucose level, $\leq 40 \mathrm{mg} / \mathrm{dL}$ (to convert to $\mathrm{mmol} / \mathrm{L}$, multiply by $0.0555)$ was significantly higher with IIT. Furthermore, the relative risk of severe hypoglycemia was 13.7 , more than twice that seen in prior randomized controlled trials., , $^{5-11}$ Thus, the incidence of hypoglycemia might be a key element of blood glucose control in critically ill patients, although no causal link between hypoglycemia and mortality has been demonstrated. However, For editorial comment, see page 215 no consensus exists on the definition of hypoglycemia in patients with critical illness. ${ }^{24}$ Studies thus far have mainly focused on severe hypoglycemia.

We sought to determine the epidemiology and independent association of hypoglycemia in the intensive care unit (ICU). We hypothesized that mild or moderate hypoglycemia would be common and would be independently associated with an increased risk of death.

\section{PATIENTS AND METHODS}

Data collection and data analysis were approved by the local institutional ethics committees, which waived the need for informed consent. The Austin Hospital Ethics Committee approved this investigation.

We conducted the study in 2 teaching hospital ICUs in Melbourne and Sydney, Australia. All patients admitted from January 1, 2000, to October 14, 2004, were included in the study. Both ICUs admitted adult medical and surgical patients, including cardiac and neurosurgical cases. We studied all patients with at least one episode of hypoglycemia (glucose concentration, $<81 \mathrm{mg} / \mathrm{dL}$ ).

As previously reported, ${ }^{25-28}$ blood glucose data were stored and retrieved electronically. Demographic, clinical, diagnostic, and outcome data were obtained from elec-

From the Department of Anesthesiology and Resuscitology, Okayama University Hospital, Okayama, Japan (M.E.); Department of Intensive Care (R.B., G.K.H., G.T.) and Department of Laboratory Medicine (C.H.), Austin Hospital, Melbourne, Victoria, Australia; Australian and New Zealand Intensive Care Research Centre and Department of Epidemiology and Preventive Medicine, Monash University, Victoria, Australia (R.B., M.B.); Department of Intensive Care, Westmead Hospital, Sydney, New South Wales, Australia (E.S.); and Department of Intensive Care, Western Hospital, Melbourne, Victoria, Australia (C.J.F.).

This study was supported by a grant from the Austin Hospital Intensive Care Trust Fund.

Individual reprints of this article are not available. Address correspondence to Rinaldo Bellomo, MD, Department of Intensive Care, Austin Health, Heidelberg, Victoria 3084, Australia (rinaldo.bellomo@austin.org.au).

(C) 2010 Mayo Foundation for Medical Education and Research 
tronic repositories. Severity of illness was assessed by the APACHE (Acute Physiology and Chronic Health Evaluation) II system. Coding for admission diagnosis was by means of a modified APACHE III system used by the Australian and New Zealand Intensive Care Society. ${ }^{29}$ The presence of infection, brain injury, and liver disease and/ or failure was categorized using prospectively collected data.

All blood glucose measurements were performed using the ICU blood gas analyzer in each hospital. Laboratories in the participating hospitals comply with quality standards of the National Association of Testing Authorities ${ }^{30}$ and Royal College of Pathologists of Australia. ${ }^{31}$ Medical staff in the ICUs initiated continuous intravenous insulin infusion, and ICU nurses adjusted the dose to maintain glucose levels between 108 and $180 \mathrm{mg} / \mathrm{dL}$. The target glycemic concentration did not change during the study period. ${ }^{27}$ In most Australian hospitals, including the study sites, the glycemic control policy did not change after the Leuven IIT study. ${ }^{32}$

For each patient, we used the minimum (lowest) blood glucose concentration recorded in the ICU. Mean and maximum ICU blood glucose concentrations were obtained or calculated. To avoid the potential effect of surveillance bias due to hypoglycemia, time-weighted glucose concentrations were used in accordance with Finney et al. ${ }^{15}$

We also calculated duration of hypoglycemia during the first and worst episodes and at any time during the ICU stay. The duration of hypoglycemia was calculated as the time after a hypoglycemic glucose level was recorded by the blood gas machine to the time when the first glucose level greater than $110 \mathrm{mg} / \mathrm{dL}$ was recorded.

Among the patients with hypoglycemia, we obtained information on insulin dose and nutritional support at the time of hypoglycemia in all nonsurvivors and in 140 randomly selected survivors. These patients were selected using a random numbers table. Nutritional support was divided into the following categories: no glucose intake, no enteral feeding but intravenous glucose intake, and enteral feeding.

\section{Cause of Death in Hypoglycemic Patients}

We obtained information on whether death was related to infection and on the proximate cause of death. Using a minor modification of the approach adopted by the NICE-SUGAR trial, ${ }^{22,23}$ we created 5 cause-of-death categories: (1) neurologic (traumatic and nontraumatic brain injury both with and without brain death), (2) cardiovascular (arrhythmia, cardiogenic shock, distributive [septic] shock and hypovolemic shock), (3) respiratory (hypoxic respiratory failure), (4) liver related (liver failure), and (5) other.

\section{Statistical Analyses}

The primary outcome of the study was hospital mortality. Two authors (M.E., R.B.) performed the initial descriptive analysis. Further statistical analysis was performed by an independent biostatistician (M.B.) not linked with the data collection. We first separated patients with hypoglycemia into survivors and nonsurvivors. Categorical variables were summarized using proportions and compared between groups using the $\chi^{2}$ test, and continuous variables were summarized using mean (SD) or median (interquartile range) and compared between groups using $t$ test or Wilcoxon rank sum test as appropriate.

Because the association between minimum blood glucose concentrations and mortality may not be linear, we created a categorical variable. Minimum blood glucose concentrations were divided into 6 bands: (1) less than $36 \mathrm{mg} / \mathrm{dL}$, (2) 36 to $45 \mathrm{mg} / \mathrm{dL}$, (3) 45 to $54 \mathrm{mg} / \mathrm{dL}$, (4) 54 to $63 \mathrm{mg} / \mathrm{dL}$, (5) 63 to $72 \mathrm{mg} / \mathrm{dL}$, and (6) 72 to $81 \mathrm{mg} / \mathrm{dL}$.

To determine the contribution of hypoglycemia to the prediction of mortality, we constructed multivariate models using all available demographic variables and potential predictors of mortality (APACHE II score, age, sex, intubation, admission type, hospital surgery type, and ICU admission date). Because a reduction in mortality was seen throughout the study period in which data were collected, ICU admission date was included in prediction models as a surrogate marker for improvement in practice over time. Length of stay was assessed dually as an independent marker of severity and to account for the increased probability of an episode of hypoglycemia due to increased testing. Furthermore, to account for the increased surveillance of the nonsurvivors, the frequency of daily measurements was included in multivariate models. To assess the impact of severity of hypoglycemic episodes, we compared the mortality in each band of severity of hypoglycemia. We report the results as odds ratio (OR) (95\% confidence interval $[\mathrm{CI}])$ and compared the areas under the receiving operating characteristic curve when hypoglycemia was added to the model. Multivariate logistic regression models were constructed using both stepwise selection and backwards elimination procedures. To increase the robustness of the prediction models, criteria were set for inclusion at $P=.01$, with all variables considered for inclusion. We determined model calibration using the Hosmer-Lemeshow goodness-of-fit test.

In patients with insulin-associated hypoglycemia, we found that the association between minimum blood glucose concentration and mortality was not linear. Because data were insufficient in this subgroup to analyze lowest blood glucose concentration as a 6-category variable, we 
stratified the data at the middle point on the graph and compared a lowest blood glucose concentration of less than 54 $\mathrm{mg} / \mathrm{dL}$ to $54 \mathrm{mg} / \mathrm{dL}$ or greater.

Data were obtained on the duration from first hypoglycemic episode to death in the ICU or discharge. We separated the hypoglycemic cohort according to this duration (short, <24 hours; long, >24 hours) and assessed the independent association between the severity of hypoglycemia and mortality in each group separately.

All analyses were performed using SAS version 9.1 (SAS Institute, Cary, NC).

\section{RESULTS}

We studied 4946 ICU patients with 125,036 glucose measurements (mean measurements/day, 5.7) and identified 1109 patients $(22.4 \%)$ with at least 1 episode of hypoglycemia. Their unadjusted hospital mortality was greater than that of the 3837 nonhypoglycemic patients (controls) (36.6\% vs 19.7\%; unadjusted OR, 2.35; 95\% CI, 2.03-2.72; $P<.001)$. A multivariate model for mortality was found to be highly discriminatory (area under the curve [AUC], 0.80) and well calibrated (Hosmer-Lemeshow statistic, $P>.05$ ). Hypoglycemia was confirmed as an independent predictor of mortality $(P=.001)$ by comparing AUC for multivariate prediction models with and without the inclusion of hypoglycemia (AUC with hypoglycemia, 0.81).

From the 1109 hypoglycemic patients, we obtained 48,866 blood glucose measurements (6.0 measurements/ day) and identified 105 patients $(9.5 \% ; 2.1 \%$ of total cohort) with severe hypoglycemia (blood glucose level, <40 $\mathrm{mg} / \mathrm{dL}$ ). Hypoglycemic patients had a mean of 1.77 hypoglycemic episodes while in the ICU (median time to recovery, 3.3 hours [interquartile range, 1.7-5.4 hours]). During time in the ICU, their blood glucose concentration was lower than $108 \mathrm{mg} / \mathrm{dL} 33.5 \%$ of the time, between 108 and $180 \mathrm{mg} / \mathrm{dL}$ (target range) $52 \%$ of the time, and higher than $180 \mathrm{mg} / \mathrm{dL} 14.5 \%$ of the time.

Clinical characteristics and glycemic control details for hospitalized survivors and nonsurvivors are listed in Table 1. Hospitalized nonsurvivors had a significantly lower minimum blood glucose concentration, more episodes of hypoglycemia, and lower glucose levels after recovery; they were more acutely ill, were older, had more measurements performed daily, and were more likely to have an infection or liver disease. The duration of any hypoglycemic episode (first episode, worst episode, and overall during ICU stay) was significantly different between survivors and nonsurvivors. Among hypoglycemic patients, there was no significant difference in mean, time-weighted average, and maximum of blood glucose concentrations between survivors and nonsurvivors.
TABLE 1. Characteristics of Hospitalized Survivors and Nonsurvivors ${ }^{\mathrm{a}}$

\begin{tabular}{|c|c|c|c|}
\hline Characteristic & Survivors & Nonsurvivors & $P$ value \\
\hline No. of patients & 703 & 406 & NA \\
\hline Male sex & $386(55)$ & $203(50)$ & .09 \\
\hline APACHE II score & $18.5(6.9)$ & $25.7(7.7)$ & $<.001$ \\
\hline $\operatorname{Age}(y)$ & $59.0(18.5)$ & $63.9(21.2)$ & $<.001$ \\
\hline Hospital A & $496(70)$ & $295(73)$ & .45 \\
\hline Hospital B & 207 (29) & $111(27)$ & .45 \\
\hline Surgical admission & $236(33)$ & $104(26)$ & .005 \\
\hline \multicolumn{4}{|l|}{ Reason for admission } \\
\hline Vascular & $138(20)$ & $83(20)$ & .75 \\
\hline Respiratory & $155(22)$ & $83(20)$ & .59 \\
\hline Trauma & $35(5)$ & $7(2)$ & .006 \\
\hline Neurologic & $76(11)$ & $34(8)$ & .21 \\
\hline Abdominal & $111(16)$ & $70(17)$ & .54 \\
\hline Other & $188(27)$ & $129(32)$ & .09 \\
\hline $\begin{array}{l}\text { Presence of liver disease } \\
\text { or failure }\end{array}$ & $42(6)$ & $38(9)$ & .04 \\
\hline Presence of infection & 205 (29) & $172(42)$ & $<.001$ \\
\hline Presence of brain injury & $65(9)$ & $30(7)$ & .28 \\
\hline Mechanical ventilation & $512(73)$ & $329(81)$ & .004 \\
\hline Diabetes mellitus & $162(23)$ & $81(20)$ & .23 \\
\hline \multicolumn{4}{|l|}{ Glucose level $(\mathrm{mg} / \mathrm{dL})^{\mathrm{b}}$} \\
\hline Minimum & $65(14)$ & $58(16)$ & $<.001$ \\
\hline Average & $135(32)$ & $135(33)$ & .92 \\
\hline Time-weighted average & $135(31)$ & $135(33)$ & .88 \\
\hline Maximum & $238(110)$ & $248(103)$ & .36 \\
\hline $\begin{array}{l}\text { Frequency of daily } \\
\text { measurements }\end{array}$ & $5.6(4.2-7.1)$ & $6.7(5.1-8.7)$ & $<.001$ \\
\hline Episodes of hypoglycemia & $1(1-2)[1.60]^{\mathrm{c}}$ & $1(1-2)[2.05]^{\mathrm{c}}$ & $<.001$ \\
\hline $\begin{array}{l}\text { Duration of first } \\
\text { episode }(\mathrm{h})\end{array}$ & $3.6(2.2-6.0)$ & $3.4(1.7-6.5)$ & .67 \\
\hline $\begin{array}{l}\text { Duration of worst } \\
\text { episode (h) }\end{array}$ & $3.8(2.4-6.4)$ & $3.6(1.9-6.5)$ & .63 \\
\hline Total duration (h) & $4.6(2.2-9.4)$ & $5.0(2.2-11.3)$ & .23 \\
\hline $\begin{array}{l}\text { Time from ICU admission } \\
\text { to first hypoglycemic } \\
\text { episode }(\mathrm{h})\end{array}$ & $33.6(12-82)$ & $28.1(10-93)$ & .47 \\
\hline Glucose level after recovery & $104(86-135)$ & $101(85-130)$ & .046 \\
\hline $\begin{array}{l}\text { Increase in glucose level } \\
\text { to recovery }\end{array}$ & $35(13-67)$ & $29(9-65)$ & .20 \\
\hline
\end{tabular}

${ }^{a}$ Categorical values are number (percentage); continuous variables are mean (SD) or median (interquartile range). APACHE $=$ Acute Physiology and Chronic Health Evaluation; ICU = intensive care unit; NA = not applicable.

${ }^{\mathrm{b}}$ SI conversion factor: To convert glucose values to $\mathrm{mmol} / \mathrm{L}$, multiply by 0.0555 .

${ }^{\mathrm{c}}$ Reported as median (interquartile range) with [mean] for increased interpretability.

The Figure shows hospital mortality according to minimum blood glucose concentration in each 9-mg/dL band. Even patients with a minimum blood glucose concentration between 72 and $81 \mathrm{mg} / \mathrm{dL}$ had a greater unadjusted mortality than did controls $(25.9 \%$ vs $19.7 \%$; OR, $1.42 ; 95 \% \mathrm{CI}$, $1.12-1.80 ; P=.004)$. Patients with a minimum blood glucose concentration lower than $63 \mathrm{mg} / \mathrm{dL}$ had a significantly higher unadjusted hospital mortality than did those with a minimum blood glucose concentration between 63 and $81 \mathrm{mg} / \mathrm{dL}$ (50.2\% vs 28.2\%; OR, 2.59; 95\% CI, 2.01-3.33; $P<.001)$. For bands below $63 \mathrm{mg} / \mathrm{dL}$, there was no significant decrease in survival with increasing severity of hypoglycemia. 


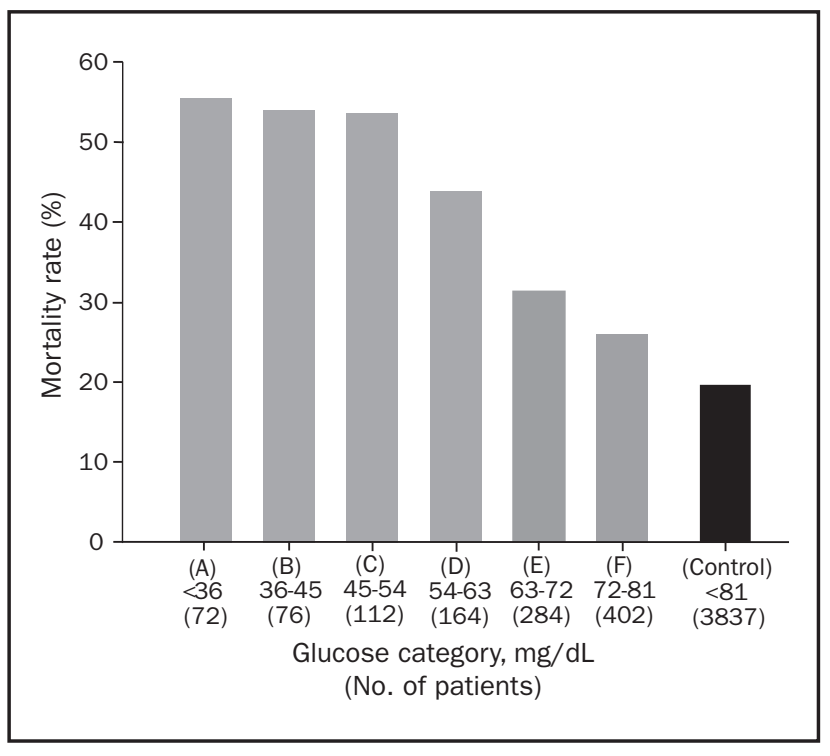

FIGURE. Hospital mortality according to severity of hypoglycemia. Gray bars indicate hospital mortality in each minimum glucose category. Black bar indicates hospital mortality in the nonhypoglycemic cohort (control). Hospital mortality was significantly higher for categories $A$ through $D$ than for categories $E$ and $F$.

In our multivariate models, illness severity and severity of hypoglycemia were independently associated with increased overall mortality, cardiovascular mortality, and mortality due to infection (Table 2). We found a similar pattern of increased risk of these deaths with increased severity of hypoglycemia.

Of the 1109 patients studied, $718(64.7 \%)$ had only a single episode of hypoglycemia. Although the number of episodes of hypoglycemia was a significant predictor of mortality at a univariate level (unadjusted OR, 1.18; $95 \%$ CI, 1.09-1.28; $P<.001)$, it was not significant in the multivariate model (adjusted OR, 1.06; 95\% CI, 0.97-1.15; $P=.22$ ). When we stratified analysis by whether patients had only one or more episodes of hypoglycemia, the minimum blood glucose concentration remained statistically significant and consistent across the strata (Table 3).

We compared patient demographic and clinical characteristics between 140 selected survivors and 715 nonselected survivors. There was no significant difference for any variable between the 2 groups. In the 394 patients for whom we had data on insulin, 129 (32.7\%) were receiving insulin at the time of hypoglycemia (insulin-associated hypoglycemia) and $265(67.3 \%)$ were not (spontaneous hypoglycemia). Characteristics of patients with spontaneous hypoglycemia and patients with insulin-associated hypoglycemia are compared in Table 4 . The cause of death was obtained in 248 ICU nonsurvivors (97.6\% of all 254 nonsurvivors, with 6 cases missing). Patients with insulin-associated hypoglycemia were more likely to have diabetes or to have brain injury at ICU admission and more likely to be hyperglycemic or to be receiving enteral nutrition at the time of hypoglycemia. They were also 3 times more likely to die of a neurologic cause. In contrast, patients with spontaneous hypoglycemia were more likely not to be receiving any nutrition at the time of the hypoglycemic episode and more likely to die of cardiovascular causes.

In the 394 patients for whom we had data on insulin dose at the time of hypoglycemia, insulin therapy was not a significant predictor of hospital mortality (66\% vs $73 \%$; unadjusted OR, 1.32; 95\% CI, 0.83-2.10; $P=.24)$. When included in a multivariate model, insulin therapy was also

TABLE 2. Multivariate Analysis of Potential Predictors of Mortality and Infection ${ }^{\text {a }}$

\begin{tabular}{|c|c|c|c|c|c|c|}
\hline Effect & $\begin{array}{l}\text { Hospital mortality, } \\
\text { OR }(95 \% \mathrm{CI})\end{array}$ & $P$ value & $\begin{array}{l}\text { ICU mortality, } \\
\text { OR }(95 \% \mathrm{CI})\end{array}$ & $P$ value & $\begin{array}{c}\text { Infection, } \\
\text { OR (95\% CI) }\end{array}$ & $P$ value \\
\hline APACHE II score & $1.13(1.11-1.15)$ & $<.001$ & $1.15(1.12-1.18)$ & $<.001$ & $1.09(1.06-1.12)$ & $<.001$ \\
\hline Diabetes & $0.70(0.49-0.99)$ & .05 & $0.35(0.22-0.57)$ & $<.001$ & $0.46(0.26-0.81)$ & .007 \\
\hline Date of admission ${ }^{b}$ & $0.92(0.86-0.98)$ & .01 & $0.87(0.80-0.95)$ & .002 & $0.86(0.78-0.95)$ & .003 \\
\hline Length of stay ${ }^{c}$ & $0.99(0.99-1.00)$ & .06 & $0.97(0.96-0.98)$ & $<.001$ & $0.99(0.98-0.99)$ & .007 \\
\hline $\begin{array}{l}\text { Frequency of daily } \\
\text { measurement }\end{array}$ & $1.07(1.02-1.12)$ & .006 & $1.12(1.06-1.19)$ & $<.001$ & $1.02(0.97-1.07)$ & .51 \\
\hline $\begin{array}{l}\text { Minimum glucose } \\
(\mathrm{mg} / \mathrm{dL})^{\mathrm{d}}\end{array}$ & & & & & & \\
\hline $0-36$ vs $72-81$ & $2.99(1.67-5.37)$ & $<.001$ & $4.10(2.05-8.19)$ & $<.001$ & $3.14(1.50-6.59)$ & .002 \\
\hline $36-45$ vs $72-81$ & $2.14(1.20-3.81)$ & .01 & $2.62(1.32-5.20)$ & .006 & $1.75(0.80-3.83)$ & .16 \\
\hline $45-54$ vs $72-81$ & $2.13(1.29-3.53)$ & .003 & $4.23(2.29-7.79)$ & $<.001$ & $3.35(1.76-6.34)$ & $<.001$ \\
\hline $54-63$ vs $72-81$ & $1.93(1.27-2.95)$ & .002 & $2.41(1.40-4.14)$ & .002 & $2.16(1.17-3.99)$ & .01 \\
\hline $63-72$ vs $72-81$ & $1.07(0.74-1.54)$ & .74 & $1.43(0.88-2.32)$ & .15 & $0.93(0.50-1.72)$ & .82 \\
\hline
\end{tabular}

${ }^{a}$ APACHE = Acute Physiology and Chronic Health Evaluation; $\mathrm{CI}=$ confidence interval; ICU = intensive care unit; OR = odds ratio.

${ }^{\mathrm{b}}$ ORs represent the risk associated with a 6-month period. Later date of admission was associated with a decreased risk.

${ }^{\mathrm{c}}$ ORs represent the risk associated with a 1-day increase in hospital length of stay. All available variables were entered into the model.

${ }^{\mathrm{d}}$ SI conversion factor: To convert glucose values to $\mathrm{mmol} / \mathrm{L}$, multiply by 0.0555 . 
TABLE 3. Risk of In-hospital Death for Patients With Only 1 Episode of Hypoglycemia $(n=718)$ vs Those With $>1$ Episode $(n=391)$, by Minimum Glucose Category ${ }^{a}$

\begin{tabular}{ccc}
\hline $\begin{array}{c}\text { Minimum glucose } \\
(\mathrm{mg} / \mathrm{dL})^{\mathrm{b}}\end{array}$ & $\begin{array}{c}\text { Single episode, } \\
\text { OR }(95 \% \mathrm{CI}) \\
\left(P=.006^{\mathrm{c}}\right)\end{array}$ & $\begin{array}{c}>1 \text { Episode, } \\
\text { OR }(95 \% \mathrm{CI}) \\
\left(P=.03^{\mathrm{c}}\right)\end{array}$ \\
\hline $0-36$ vs $72-81$ & $3.53(1.60-7.79)$ & $2.67(1.00-7.13)$ \\
$36-45$ vs $72-81$ & $1.62(0.65-4.00)$ & $2.76(1.14-6.72)$ \\
$45-54$ vs 72-81 & $2.28(1.11-4.67)$ & $2.21(0.95-5.13)$ \\
$54-63$ vs 72-81 & $1.34(0.77-2.35)$ & $3.38(1.55-7.38)$ \\
$63-72$ vs 72-81 & $0.89(0.57-1.41)$ & $1.50(0.72-3.12)$ \\
\hline
\end{tabular}

${ }^{a}$ All available variables were entered into the model. $\mathrm{OR}=$ odds ratio; $\mathrm{CI}=$ confidence interval.

${ }^{\mathrm{b}}$ SI conversion factor: To convert glucose values to $\mathrm{mmol} / \mathrm{L}$, multiply by 0.0555 .

${ }^{\mathrm{c}}$ For significance of minimum blood glucose concentration after adjustment for Acute Physiology and Chronic Health Evaluation II score, diabetes, date of admission, length of stay, and frequency of daily measurements.

not a significant predictor of hospital mortality (OR, 0.82; 95\% CI, 0.47-1.42; $P=.48$ ), but minimum blood glucose concentration remained a predictor of mortality. In the presence of insulin, patients with glucose levels lower than $54 \mathrm{mg} / \mathrm{dL}$ had independently twice the risk of hospital mortality (adjusted OR, 2.00; 95\% CI, 1.11-3.67; $P=.02$ ). There was no significant interaction between minimum blood glucose concentration and insulin; when patients receiving insulin were analyzed separately, results remained similar.

The median time between admission and the first episode of hypoglycemia was 32 hours (range, 12-89 hours), with $42.6 \%$ of first episodes occurring within 24 hours and $61.2 \%$ within 48 hours of ICU admission. Among nonsurvivors, the median time from last hypoglycemic episode to death was 16 hours (range, 5-60 hours). The first hypoglycemic episode occurred less than 24 hours before ICU death or discharge in 342 patients and more than 24 hours earlier in 767 patients. The median duration of this interval was 9 hours and 105 hours, respectively, in the 2 cohorts. The "short-duration" cohort had a significantly higher mortality than the long-duration cohort (43.5\% vs $33.9 \%$; unadjusted OR, 1.48; 95\% CI, 1.14-1.92; $P=.001)$. Compared with controls, both cohorts had a significantly higher unadjusted mortality rate (unadjusted OR, 3.11; 95\%, 2.47-3.91; and OR, $2.10 ; 95 \% \mathrm{CI}, 1.77-2.49$, respectively; $P<.001)$. In the long-duration cohort, the categorical variable for severity of hypoglycemia was significantly associated with death $(P=.008)$; however, in the short-duration cohort, there was no significant association $(P=.35)$.

\section{DISCUSSION}

We sought to understand the epidemiology, severity, duration, recovery, and outcome associations of hypoglycemia
TABLE 4. Comparison of Spontaneous and Insulin-Associated Hypoglycemia ${ }^{a}$

\begin{tabular}{|c|c|c|c|}
\hline & $\begin{array}{l}\text { Insulin- } \\
\text { associated }\end{array}$ & Spontaneous & $\begin{array}{c}P \\
\text { value }\end{array}$ \\
\hline No. of patients & 129 & 265 & NA \\
\hline Male sex & $77(60)$ & $130(49)$ & .047 \\
\hline APACHE II score & $23.0(7.4)$ & $25.2(8.9)$ & .02 \\
\hline Age (y) & $66.1(13.7)$ & $60.9(17.7)$ & .004 \\
\hline Surgical admission & $36(28)$ & $77(29)$ & .80 \\
\hline \multicolumn{4}{|l|}{ Reason for admission } \\
\hline Vascular & $32(25)$ & $58(22)$ & .52 \\
\hline Respiratory & $30(23)$ & $38(14)$ & .03 \\
\hline Trauma & $4(3)$ & $4(2)$ & .29 \\
\hline Neurologic & $18(14)$ & $22(8)$ & .08 \\
\hline Abdominal & $16(12)$ & $51(19)$ & .09 \\
\hline Other & $29(22)$ & $92(35)$ & .01 \\
\hline \multicolumn{4}{|l|}{ Presence of liver disease } \\
\hline Presence of infection & $56(43)$ & $134(51)$ & .18 \\
\hline Presence of brain injury & $26(20)$ & $29(11)$ & .01 \\
\hline Mechanical ventilation & $113(88)$ & $211(80)$ & .05 \\
\hline Diabetes mellitus & $35(27)$ & $36(14)$ & .001 \\
\hline \multicolumn{4}{|l|}{ Glucose level $(\mathrm{mg} / \mathrm{dL})^{\mathrm{b}}$} \\
\hline Minimum & $58(16)$ & $59(16)$ & .52 \\
\hline Average & $153(29)$ & $124(32)$ & $<.001$ \\
\hline Time-weighted average & $149(25)$ & $124(32)$ & $<.001$ \\
\hline Maximum & $293(112)$ & $211(83)$ & $<.001$ \\
\hline Frequency of daily glucose & $7.2(5.9-8.6)$ & $6.7(4.5-9.4)$ & .09 \\
\hline Episodes of hypoglycemia & $1(1-2.3)$ & $1(1-2)$ & .80 \\
\hline No glucose intake & $61(47)$ & $195(74)$ & $<.001$ \\
\hline Parenteral nutrition & $17(13)$ & 37 (14) & .83 \\
\hline Enteral nutrition & $51(40)$ & $33(12)$ & $<.001$ \\
\hline ICU mortality & $77(60)$ & $177(67)$ & .17 \\
\hline Hospital mortality & $85(66)$ & $193(73)$ & .16 \\
\hline \multicolumn{4}{|l|}{$\begin{array}{l}\text { COD among } 248 \text { ICU } \\
\text { nonsurvivors }\end{array}$} \\
\hline Infection related & $33(42.9)$ & $95(55.6)$ & .12 \\
\hline \multicolumn{4}{|l|}{ COD categories } \\
\hline Cardiovascular & $38(49.4)$ & $123(71.9)$ & .001 \\
\hline Liver failure & $4(5.2)$ & $10(5.8)$ & .67 \\
\hline Neurologic & $22(28.6)$ & $18(10.5)$ & $<.001$ \\
\hline Respiratory & $4(5.2)$ & $10(6.4)$ & .97 \\
\hline Other & $9(11.7)$ & $10(5.8)$ & .19 \\
\hline
\end{tabular}

${ }^{a}$ Categorical values are number (percentage); continuous variables are mean (SD) or median (interquartile range). APACHE = Acute Physiology and Chronic Health Evaluation; COD = cause of death; ICU = intensive care unit; NA = not applicable.

${ }^{\mathrm{b}}$ SI conversion factor: To convert glucose values to $\mathrm{mmol} / \mathrm{L}$, multiply by 0.0555 .

in critically ill patients. We found that $22.4 \%$ of patients experienced at least one blood glucose value less than 81 $\mathrm{mg} / \mathrm{dL}$ and $2.1 \%$ sustained at least one value less than 40 $\mathrm{mg} / \mathrm{dL}$. Hypoglycemia had an increased adjusted risk of hospital death, and its severity (whether spontaneous or insulin-associated) was independently associated with higher mortality. In contrast, among patients with hypoglycemia, maximum, mean, and time-weighted average blood glucose concentrations were not significantly associated with mortality. Our observations suggest that even mild or moderate hypoglycemia (either spontaneous or insulin-associated) is an independent predictor of hospital mortality. 


\section{Strengths And Limitations}

Our study has several strengths. All glucose values were measured with arterial blood gas analyzers, reducing the error associated with capillary blood measurement with point-of-care devices. We provided a detailed analysis of different increments of hypoglycemia and an analysis of insulin-associated vs non-insulin-associated hypoglycemia. In addition, information was provided on nutrition at the time of hypoglycemia, and data were provided relating timing of the hypoglycemic episode and death. To our knowledge, these characteristics combined with the magnitude of the data make our study the most comprehensive analysis of hypoglycemia in critically ill patients to date.

However, our study has several limitations. It is retrospective in design and thus potentially subject to systematic error and bias. Nonetheless, study data were collected prospectively and independently, are numerical, and are not amenable to selection bias. Because this is an observational study, the associations described cannot be taken to indicate causality. Thus, the unadjusted and adjusted associations between hypoglycemia and mortality cannot be taken to indicate a causal link; hypoglycemia might simply be a strong marker of illness severity. However, observational studies using multivariate logistic analysis remain the current "best" approach to assessing the possible effect of hypoglycemia on outcome (ie, conducting a randomized controlled study of induced hypoglycemia in humans would not be feasible or ethical).

Our study involved only 2 centers, where a target blood glucose level was between 108 and $180 \mathrm{mg} / \mathrm{dL}$. Thus, our findings might not be generalized to other target levels. However, recent recommendations for acute glycemic control appeared to be less than $180 \mathrm{mg} / \mathrm{dL}$, which is similar to that for our cohorts. In this regard, our findings might be important. ${ }^{33}$ Furthermore, irrespective of the target level, hypoglycemia has been reported with a frequency similar to or greater than ours in all studies of glucose control thus far, except for the control arm of the NICE-SUGAR trial, suggesting that worldwide many patients in the ICU are regularly exposed to the risks of hypoglycemia.

We selected all nonsurvivors and randomly selected only 140 survivors to obtain insulin and nutritional information at the time of hypoglycemia. However, these randomly selected survivors showed no significant difference when compared with nonselected survivors.

\section{Comparison With Previous Studies}

The incidence of severe hypoglycemia has repeatedly been shown to increase whenever clinicians target lower glucose concentrations or normoglycemia. ${ }^{5,9-11,22,34}$ Severe or prolonged hypoglycemia can result in cardiac arrhythmias, convulsions, irreversible brain damage, and death. Accord- ingly, hypoglycemia is of great concern when delivering continuous insulin infusions to sedated ICU patients. In the second Leuven trial ${ }^{10}$ and in the VISEP (Efficacy of Volume Substitution and Insulin Therapy in Severe Sepsis) trial, ${ }^{5}$ the incidence of severe hypoglycemia was associated with an increased adjusted risk of mortality.

In contrast with all these findings and with those of our study, a multivariate logistic regression model used in the case-control study performed by Vriesendorp et $\mathrm{al}^{35}$ concluded that severe hypoglycemia $(n=156)$ did not confer an increased risk of mortality. The study's methodology (case-matched control study) and limited power might have contributed to this different conclusion. Recently, in a study of patients with myocardial infarction, Kosiborod et $\mathrm{al}^{36}$ reported that, although spontaneous hypoglycemia was associated with a greater risk of death, hypoglycemia associated with insulin therapy was not. However, that study dealt with a population of awake and alert patients receiving subcutaneous and discontinuous insulin. It was also underpowered to detect an effect of insulin-associated hypoglycemia on mortality (only 36 deaths among 346 hypoglycemic patients). In contrast, we studied more than 10 times as many deaths among 1109 hypoglycemic patients.

\section{Clinical Implications}

At least 3 possible explanations exist for the association between hypoglycemia and outcome that we and others have observed. First, severity of hypoglycemia may be associated with severity of illness. ${ }^{37}$ Second, hypoglycemia may be a biomarker of imminent death. Our results suggest otherwise because hypoglycemia that occurred a median of 105 hours before death in the ICU or before discharge was still independently associated with increased mortality, even after adjustments for severity of illness and demographics. Third, hypoglycemia might have a true deleterious biologic effect in critically ill patients. For example, hypoglycemic episodes might have biologic toxicity by increasing the systemic inflammatory response, ${ }^{38}$ inducing neuroglycopenia, ${ }^{39}$ inhibiting the corticosteroid response to stress, ${ }^{40}$ impairing sympathetic system responsiveness, ${ }^{41}$ causing cerebral vasodilatation, ${ }^{42}$ or other yet unidentified mechanisms. Finally, any combination of these factors might apply.

Our results suggest that any tolerance of mild or moderate hypoglycemia by intensive care clinicians may be undesirable. In this regard, newer technologies such as continuous glucose monitoring in the ICU setting might help avoid hypoglycemia or identify it earlier. Of particular interest in keeping with our findings, the NICE-SUGAR trial reported an increase both in severe hypoglycemia and in cardiovascular deaths when clinicians targeted normoglycemia. ${ }^{22,23}$ Furthermore, given our finding that severe hypoglycemia repre- 
sents less than $10 \%$ of all episodes of hypoglycemia and the $6.8 \%$ reported incidence of severe hypoglycemia in the IIT arm of the NICE-SUGAR trial, it is theoretically possible that about two-thirds of patients in the IIT arm of the NICESUGAR trial experienced an episode of hypoglycemia. The contribution of such a dramatic hypoglycemic burden to outcome requires careful exploration.

About one-third of cases of hypoglycemia in our study were insulin-associated. Our observations suggest an iatrogenic component combined with physiologically predisposing factors. In these patients, the independent association between hypoglycemia and mortality remained significant and related to severity of hypoglycemia. Furthermore, in comparison with spontaneous hypoglycemia, insulin-associated hypoglycemia showed a trend toward a link with a higher rate of neurologic deaths. These observations and concerns about neuroglycopenia ${ }^{39}$ and about the effect of hypoglycemia-associated cerebral hyperemia $\mathrm{a}^{42}$ raise the possibility that insulin-associated hypoglycemia may independently contribute to increased mortality. In this regard, in patients with traumatic brain injury, tight systemic glucose control with insulin is associated with reduced cerebral extracellular glucose availability and increased prevalence of brain energy crises, events that correlate with increased mortality. ${ }^{43}$ Alternatively, because insulin-associated hypoglycemia was more common in patients with neurologic disease, such patients may simply be more prone to insulin-associated hypoglycemia either because of their decreased level of consciousness or because of other, unexplained mechanisms. Finally, both increased risk and increased injury might be present in these patients, making this association particularly complex.

\section{Future StUdies}

Further studies are needed to increase our understanding of hypoglycemia in the critically ill, possibly using the NICESUGAR trial database. ${ }^{44,45}$ They should particularly focus on the mechanistic association between hypoglycemia and outcomes. Prospective studies of the same question in a large cohort of ICU patients are also desirable. Finally, given developments in technology, it is now important to investigate the role of continuous glucose monitoring in the ICU setting, especially in identifying hypoglycemia not detected by infrequent bedside glucose testing.

\section{CONCLUSION}

We found an independent association between even mild or moderate hypoglycemia and mortality. This association persisted after adjustment for insulin therapy. In hypoglycemic patients, severity of hypoglycemia was independently associated with mortality, but severity of hyperglycemia was not. The association between hypoglycemia and mortality remained even after patients who had hypoglycemia in the 24 hours before death were excluded. One-third of episodes of hypoglycemia were insulin-associated, occurring with greater frequency in diabetic patients and in those receiving enteral nutrition, suggesting an iatrogenic component.

We acknowledge the assistance of the ICU nurses who performed all measurements.

\section{REFERENCES}

1. Dellinger RP, Carlet JM, Masur H, et al. Surviving Sepsis Campaign guidelines for management of severe sepsis and septic shock. Crit Care Med. 2004;32:858-873

2. Dellinger RP, Levy MM, Carlet JM, et al; International Surviving Sepsis Campaign Guidelines Committee. Surviving Sepsis Campaign: international guidelines for management of severe sepsis and septic shock: 2008 [published correction appears in Crit Care Med. 2008;36(4):1394-1396]. Crit Care Med. 2008;36(1):296-327.

3. Garber AJ, Moghissi ES, Bransome ED Jr, et al. American College of Endocrinology position statement on inpatient diabetes and metabolic control. Endocr Pract. 2004;10:77-82.

4. Bilotta F, Caramia R, Cernak I, et al. Intensive insulin therapy after severe traumatic brain injury: a randomized clinical trial. Neurocrit Care. 2008;9(2):156-166.

5. Brunkhorst FM, Engel C, Bloos F, et al. Intensive insulin therapy and pentastarch resuscitation in severe sepsis. N Engl J Med. 2008;358:125-139.

6. Oksanen T, Skrifvars MB, Varpula T, et al. Strict versus moderate glucose control after resuscitation from ventricular fibrillation. Intensive Care Med. 2007;33:2093-2100.

7. Mitchell I, Knight E, Gissane J, et al. A phase II randomised controlled trial of intensive insulin therapy in general intensive care patients. Crit Care Resusc. 2006;8:289-293.

8. Van den Berghe G, Wilmer A, Milants I, et al. Intensive insulin therapy in mixed medical/surgical intensive care units: benefit versus harm. Diabetes. 2006;55:3151-3159.

9. van den Berghe G, Wouters $P$, Weekers F, et al. Intensive insulin therapy in critically ill patients. $N$ Engl J Med. 2001;345:1359-1367.

10. Van den Berghe G, Wilmer A, Hermans G, et al. Intensive insulin therapy in the medical ICU. $N$ Engl J Med. 2006;354:449-461.

11. Preiser JC, Devos P, Ruiz-Santana S, et al. A prospective randomised multi-centre controlled trial on tight glucose control by intensive insulin therapy in adult intensive care units: the Glucontrol study. Intensive Care Med. 2009;35(10): 1738-1748.

12. Krinsley JS. Association between hyperglycemia and increased hospital mortality in a heterogeneous population of critically ill patients. Mayo Clin Proc. 2003;78:1471-1478.

13. Bochicchio GV, Sung J, Joshi M, et al. Persistent hyperglycemia is predictive of outcome in critically ill trauma patients. J Trauma. 2005;58:921924.

14. Gore DC, Chinkes D, Heggers J, Herndon DN, Wolf SE, Desai M. Association of hyperglycemia with increased mortality after severe burn injury. $J$ Trauma. 2001;51:540-544

15. Finney SJ, Zekveld C, Elia A, Evans TW. Glucose control and mortality in critically ill patients. JAMA. 2003;290:2041-2047.

16. Egi M, Morimatsu H, Toda Y, et al. Hyperglycemia and the outcome of pediatric cardiac surgery patients requiring peritoneal dialysis. Int J Artif Organs. 2008;31:309-316.

17. Krinsley JS, Grover A. Severe hypoglycemia in critically ill patients: risk factors and outcomes. Crit Care Med. 2007;35:2262-2267.

18. Wintergerst KA, Buckingham B, Gandrud L, Wong BJ, Kache S, Wilson DM. Association of hypoglycemia, hyperglycemia, and glucose variability with morbidity and death in the pediatric intensive care unit. Pediatrics. 2006;118:173-179. 
19. Bhatia A, Cadman B, Mackenzie I. Hypoglycemia and cardiac arrest in a critically ill patient on strict glycemic control. Anesth Analg. 2006;102: 549-551.

20. Dowdy DW, Dinglas V, Mendez-Tellez PA, et al. Intensive care unit hypoglycemia predicts depression during early recovery from acute lung injury. Crit Care Med. 2008;36:2726-2733.

21. Bagshaw SM, Bellomo R, Jacka MJ, et al; ANZICS CORE Management Committee. The impact of early hypoglycemia and blood glucose variability on outcome in critical illness. Crit Care. 2009;13:R91. doi:10.1186/cc7921.

22. Finfer S, Chittock DR, Su SY, et al. Intensive versus conventional glucose control in critically ill patients. N Engl J Med. 2009;360:1283-1297.

23. Finfer S, Heritier S. The NICE-SUGAR (Normoglycaemia in Intensive Care Evaluation and Survival Using Glucose Algorithm Regulation) Study: statistical analysis plan. Crit Care Resusc. 2009;11:46-57.

24. Hirshberg E, Lacroix J, Sward K, Willson D, Morris AH. Blood glucose control in critically ill adults and children: a survey on stated practice. Chest. 2008;133(6):1328-1335.

25. Egi M, Bellomo R, Stachowski E, French CJ, Hart G. Variability of Blood Glucose Concentration and Short-term Mortality in Critically Ill Patients. Anesthesiology. 2006;105:244-252.

26. Egi M, Bellomo R, Stachowski E, French CJ, Hart G, Stow P. Circadian rhythm of blood glucose values in critically ill patients. Crit Care Med. 2007;35:416-421.

27. Egi M, Bellomo R, Stachowski E, et al. Intensive insulin therapy in postoperative intensive care unit patients: a decision analysis. Am J Respir Crit Care Med. 2006;173:407-413.

28. Egi M, Bellomo R, Stachowski E, et al. Blood glucose concentration and outcome of critical illness: the impact of diabetes. Crit Care Med. 2008;36:2249-2255.

29. Australian and New Zealand Intensive Care Society (ANZICS). ANZICS Web site. http://www.anzics.com.au. Accessed January 13, 2010.

30. National Association of Testing Authorities. NATA Web site. http:// www.nata.asn.au/. Accessed January 13, 2010.

31. Royal College of Pathologists of Australia. RCPA Web site. http://www .rcpa.edu.au/Home.htm. Accessed January 13, 2010.

32. Bagshaw SM, Egi M, George C, Bellomo R. Early blood glucose control and mortality in critically ill patients in Australia. Crit Care Med. 2009;37:463-470.
33. Moghissi ES, Korytkowski MT, DiNardo M, et al. American Association of Clinical Endocrinologists and American Diabetes Association consensus statement on inpatient glycemic control. Endocr Pract. 2009;15:353-369.

34. Griesdale DE, de Souza RJ, van Dam RM, et al. Intensive insulin therapy and mortality among critically ill patients: a meta-analysis including NICESUGAR study data. CMAJ. 2009;180:821-827, discussion 799-800.

35. Vriesendorp TM, DeVries JH, van Santen S, et al. Evaluation of shortterm consequences of hypoglycemia in an intensive care unit. Crit Care Med. 2006;34:2714-2718.

36. Kosiborod M, Inzucchi SE, Goyal A, et al. Relationship between spontaneous and iatrogenic hypoglycemia and mortality in patients hospitalized with acute myocardial infarction. JAMA. 2009;301:1556-1564.

37. Vriesendorp TM, van Santen S, DeVries JH, et al. Predisposing factors for hypoglycemia in the intensive care unit. Crit Care Med. 2006;34:96-101.

38. Dotson S, Freeman R, Failing HJ, Adler GK. Hypoglycemia increases serum interleukin-6 levels in healthy men and women. Diabetes Care. 2008;31:1222-1223.

39. Schlenk F, Graetz D, Nagel A, Schmidt M, Sarrafzadeh AS. Insulinrelated decrease in cerebral glucose despite normoglycemia in aneurysmal subarachnoid hemorrhage. Crit Care. 2008;12:R9. doi:10.1186/cc6776.

40. Keller-Wood ME, Shinsako J, Dallman MF. Inhibition of the adrenocorticotropin and corticosteroid responses to hypoglycemia after prior stress. Endocrinology. 1983;113:491-496.

41. Herlein JA, Morgan DA, Phillips BG, Haynes WG, Sivitz WI. Antecedent hypoglycemia, catecholamine depletion, and subsequent sympathetic neural responses. Endocrinology. 2006;147:2781-2788.

42. Dieguez G, Fernandez N, Garcia JL, Garcia-Villalon AL, Monge L, Gomez B. Role of nitric oxide in the effects of hypoglycemia on the cerebral circulation in awake goats. Eur J Pharmacol. 1997;330:185-193.

43. Oddo M, Schmidt JM, Carrera E, et al. Impact of tight glycemic control on cerebral glucose metabolism after severe brain injury: a microdialysis study. Crit Care Med. 2008;36:3233-3238.

44. Myburgh JA, Chittock DR. Differences in outcome between the NICESUGAR and Leuven trials: biological mechanisms of intensive glucose control in critically ill patients. Crit Care Resusc. 2009;11:178-179.

45. Henderson WR, Finfer S. Differences in outcome between the NICESUGAR and Leuven trials: possible methodological explanations. Crit Care Resusc. 2009;11:175-177. 